EGU21-12799

EGU General Assembly 2021

(c) Author(s) 2021. This work is distributed under

the Creative Commons Attribution 4.0 License.

\title{
From landslide characterization to nature reserve management: The Scialimata Grande landslide Geosite (Central Appennine, Italy)
}

\author{
Gianluca Tronti ${ }^{1}$, Irene Maria Bollati ${ }^{2}$, Manuela Pelfini ${ }^{3}$, Filippo Belisario ${ }^{4}$, and Paola Fredi ${ }^{5}$ \\ ${ }^{1}$ Earth Sciences Department Ardito Desio, University La Statale, Milan, Italy (gianluca.tronti@unimi.it) \\ ${ }^{2}$ Earth Sciences Department Ardito Desio, University La Statale, Milan, Italy (irene.bollati@unimi.it) \\ ${ }^{3}$ Earth Sciences Department Ardito Desio, University La Statale, Milan, Italy (manuela.pelfini@unimi.it) \\ ${ }^{4}$ Monte Rufeno Nature Reserve, Viterbo, Italy (fbelisario@regione.lazio.it) \\ ${ }^{5}$ Earth Sciences Department, University La Sapienza, Rome, Italy (paola.fredi@fondazione.uniroma1.it)
}

The Italian territory is characterized by frequent hydrogeological instability phenomena, among which landslides, responsible for a high number of damages, are able to leave impressive marks on the landscape and to rework the physical features of a territory. Nevertheless, landslide bodies may represent key sites for thematic itineraries, educational projects, and valorization especially in protected areas. Their management can consequently become an important issue in natural reserves' management.

Our study focuses on the territory of the "Monte Rufeno Nature Reserve" (Central Apennines, Italy), where iconic landslides are present. Here, the "Scialimata Grande di Torre Alfina" landslide, is listed in the regional Geosite database. After creating a landslide susceptibility map for the reserve territory - based on drainage density and relief energy - the analysis was focused on the Scialimata complex landslide, to define properly its scientific and educational value. The geomorphological characterization of the landslide - carried out both on the field (geomorphological survey and GPS monitoring through wooden pins) that through remote sensing techniques (UAV drone, photointerpretation) - helped the assessment of the landslide dynamism. Moreover, dendrogeomorphological and ecological characterizations were performed to understand the relations between the geomorphic dynamics and the vegetation response (i.e., ecological support role of the Geosite). The area affected by Scialimata landslide falls into the highest landslide susceptibility class. At the local scale, its recent dynamics - as resulted from the GPS field monitoring in the 2015-2018 time interval - shows a maximum downvalley displacement of 23 meters. The landslide dynamics could be driven by a rain pattern with alternated dry and extremely wet periods; moreover, leakages from the water pipeline in proximity of the landslide crowning area, may have decreased the clays cohesion. The possible influence of the landslide, on the Paglia River dynamics, downvalley, was also hypothesized. Disturbances on plants ascribable to the landsliding, as tilted trunks and exposed roots, show distribution and characters explainable not only by the complex rotational dynamism of the landslide, but also by the hypothesized piping effect in the crowning zone. The landslide is highly representative of the geomorphic dynamics affecting the natural Reserve (i.e., scientific value) and it could be classified as an active Geosite, featured by a high ecological support role (not only towards vegetation) that increases the 
scientific value of the site too. Since the site was also featured by a touristic trail, that underwent disruption due to landslide movement, these results could enable adequate management strategies considering educational value and safety issues. 